Palavras chave: Aroeira Esclerofilia foliar Plantas medicinais Anatomia ecológica

Histórico:

Recebido 04/05/2012

Aceito 14/04/2014

Keywords: Aroeira

Leaf sclerophylly

Medical plants

Ecological anatomy

Correspondência: fabriciopereira@dbi.ufla.br

DOI: I0.1590/0104776020152101 I530
Marinês Ferreira Pires', Márcio Paulo Pereira', Evaristo Mauro de Castro', Sandro Barbosa², Fabricio José Pereira'

\section{MICROMORFOMETRIA FOLIAR DE Schinus molle L. (ANARCADIACEAE) EM DIFERENTES ALTURAS NA COPA}

RESUMO: A caracterização foliar em árvores é essencial para a sua identificação e utilização, bem como para se compreender as suas relações com o ambiente. Neste trabalho, objetivou-se o estudo da anatomia dos folíolos e das características biométricas das folhas de $S$. molle em diferentes alturas na copa, em função das modificações ambientais e fisiológicas promovidas. As folhas foram coletadas em três diferentes alturas na copa: base, meio e alto da copa em uma população cultivada de S. molle. Para as analises anatômicas, as folhas foram fixadas em FAA e armazenadas em etanol sendo, posteriormente, submetidas a secções paradérmicas e transversais. As lâminas foram fotomicrografadas e as imagens analisadas no software UTHSCSA-Imagetool. Para as análises biométricas foram avaliadas a área, comprimento, largura, massa seca foliares, bem como a área foliar específica. Os folíolos possuem epiderme unisseriada, estômatos anomocíticos e ciclocíticos, mesofilo isobilateral e camada subepidérmica em ambas as faces da epiderme. Canais secretores e colênquima foram observados na nervura central e bordo dos folíolos. Ocorreram modificações nas espessuras da cutícula e do mesofilo, no sistema vascular, espessura do floema e na densidade estomática de acordo com a altura em que os folíolos se encontram na copa das árvores. As folhas foram menores e demonstram reduzida área foliar para as partes mais altas da copa. A anatomia foliar de $S$. molle é diferente de outras espécies do gênero Schinus e demonstra modificações sob as diferentes condições ambientais e fisiológicas promovidas pelas diferentes alturas na copa.

\section{LEAF MICROMORPHOMETRY OF Schinus molle L. (ANARCADIACEAE) IN DIFFERENT CANOPY HEIGHTS.}

ABSTRACT: Leaf characterization of trees is essential for its identification and use, as well as to understand its relationships with environment. The objective of this work is to study the leaflet anatomy and leaf biometrical characteristics at different canopy heights of Schinus molle plants as a function of its environmental and physiological modifications. Leaves were collected at three different canopy heights: base, middle and upper canopy in a plantation of S. molle. Leaves were used for anatomical and biometrical analysis. For the anatomical analysis, leaves were fixed in FAA and stored in ethanol $70 \%$ and further submitted to transversal and paradermical sections. Slides were photomicrographed and image analysis was performed in UTHSCSA-Imagetool. For biometrical analysis leaf area, length, width, dry mass and specific leaf area were evaluated. The leaflets exhibited single layer epidermis, anomocytic and ciclocytic stomata, isobilateral mesophyll, subepidermal parenchyma layer in both adaxial and abaxial faces of epidermis, secretory vessels and lamellar collenchyma in midrib and leaf border. Leaf anatomy modifications occurred in cuticle and mesophyll thickness, vascular system, phloem thickness, and stomatal density in accordance with leaf canopy position. Leaves were smaller and with reduced leaf area at higher canopy positions. S. molle leaf anatomy is different from other species within Schinus genre with modifications under different environmental and physiological modifications promoted by its canopy height.

' Universidade Federal de Lavras - Lavras, Minas Gerais, Brasil

${ }^{2}$ Universidade Federal de Alfenas - Alfenas, Minas Gerais, Brasil 


\section{INTRODUÇÃO}

O gênero Schinus L. pertence à família Anacardiaceae e contém 37 espécies presentes, desde a América Central até a Argentina (MACHADO et al., 2008). A espécie Schinus molle é conhecida, popularmente, como aroeira salsa ou aroeirinha, apresentando hábito arbóreo com cerca de 8-20 m com copa globosa, densa, perenifólia, com folhas compostas, pinatífidas. Possui crescimento relativamente rápido, em média I $\mathrm{m}$ por ano, com tronco de 30-80 cm de diâmetro (LORENZI, 1992).

A composição química de óleos essenciais das folhas e frutos de $S$. molle inclui várias substâncias que apresentam atividades de interesse farmacêutico (MARONGIU et al., 2004). Os componentes majoritários do óleo essencial de S. molle foram identificados como $\alpha$-pineno, $\beta$-pineno, mirceno, limoneno, $\beta$-cariofileno, biciclogermacreno, $\delta$-cadineno, espatulenol e $\alpha$-cadinol (SANTOS et al., 2007). Essa composição química pode variar em diferentes populações da planta, fator associado a diferenças no ambiente e no genótipo dos indivíduos (BEZERRA et al., 2008).

A anatomia de plantas do gênero Schinus vem sendo estudada, tendo em vista a necessidade de se conhecer a estrutura interna dessas plantas para a correta utilização na indústria farmacêutica e para se conhecer, de forma adequada, as variações interespecíficas. Existe um crescente interesse em dados sobre anatomia foliar de árvores com potencial medicinal para o uso diagnóstico (ARAMBARRI et al., 2006). A espécie Schinus longifolia var. longifolia apresenta estômatos anomocíticos, canais resiníferos, mesofilo dorsiventral, epiderme uniestratificada com presença de cutícula desenvolvida e tricomas (PERROTA; ARAMBARRI, 2004). Diferenças na anatomia foliar podem ocorrer em relação à sua posição na planta, e isso pode refletir em características fisiológicas, como na fotossíntese e produção de compostos secundários (LARCHER, 2004). Estudos morfológicos como os anatômicos são importantes para a produção e manejo das espécies florestais (CAMARGO et al., 2000).

Diferentes posições na copa em função da altura da árvore estão relacionadas a variações ambientais como na intensidade luminosa, disponibilidade hídrica, temperatura do ar, pressão de vapor e/ou velocidade do vento (KIRA; YODA, 1989). Geralmente, há maior disponibilidade de luz com o aumento na altura da árvore (KING, 1990), enquanto a condutividade hidráulica diminui (ENGLAND; ATTIWILL, 2006; HUBBARD et al., 1999). A redução na condutividade hidráulica pode levar a uma redução na disponibilidade de nutrientes e, todas essas diferentes condições, podem levar a modificações morfofisiológicas nas folhas. Segundo Dias et al. (2007), folhas de porções da copa de árvores que exibem maior intensidade de radiação (folhas de sol) demonstram modificações no conteúdo de clorofila, nas características de trocas gasosas como a transpiração e nas condições nutricionais. Essas modificações nas características fotossintéticas podem estar relacionadas a modificações anatômicas como folhas mais espessas e com maior proporção de mesofilo em folhas de sol (KUBÍNOVÁ, 199I). Além de maior espessura foliar e do mesofilo, plantas submetidas a maiores intensidade de radiação, podem promover maior deposição de ceras epicutilicares, relacionadas à diminuição da transpiração excessiva (PAIVA et al., 2003). Plantas de Schinus terebinthifolius podem apresentar maior espessura do mesofilo, da cutícula e do parênquima paliçádico em ambientes mais abertos em comparação a ambientes mais sombreados (SABBI et al., 20I0).

Apesar da anatomia de algumas espécies do gênero Schinus ter sido estudada, não existem trabalhos que relatem a anatomia foliar de $S$. molle, nem as possíveis variações da estrutura interna das folhas em diferentes alturas na planta. Nesse contexto, neste trabalho, objetivou-se descrever a anatomia foliar de S. molle e as possíveis modificações quantitativas nos tecidos foliares, dependendo das variações ambientais e fisiológicas decorrentes da altura na copa.

\section{MATERIAL E MÉTODOS}

As plantas de Schinus molle L. foram amostradas em população utilizada para arborização urbana em Alfenas - MG, plantadas em canteiros centrais, em condições de pleno sol, sem qualquer sombreamento ao longo do dia. Foram sorteadas 10 plantas e coletadas 4 folhas, completamente expandidas, localizadas nos pontos cardeais leste, oeste, norte e sul em 3 alturas na porção mais externa dos ramos: a l,30 m (base da copa), I,8 m (meio da copa) e a 2,30 m (alto da copa). Foram coletadas folhas para a análise anatômica e para análise biométrica das folhas nas diferentes alturas na copa. As amostras foram coletadas, em maio de 2008, sendo confeccionada exsicata que foi depositada no herbário da Universidade Federal de Alfenas (Unifal-MG) n HUNIFAL298.

Para as análises anatômicas, as folhas foram fixadas em $\mathrm{FAA}_{70}$ (JOHANSEN, 1940) por um período de 48 h, sendo, então, transferidas para etanol 70\%, até a data das análises. Foram realizadas secções paradérmicas 
à mão livre das faces abaxial e adaxial da epiderme e, ainda, secções transversais em micrótomo de mesa, no quarto par de folíolos, a partir da base da folha, com auxílio de lâminas de aço descartáveis, no Laboratório de Anatomia Vegetal da Universidade Federal de Lavras (MELO et al., 2007). As secções foram clarificadas em hipoclorito de sódio $50 \%$ por 10 minutos, lavadas duas vezes em água destilada por 10 minutos, coradas com safranina $1 \%$ (secções paradérmicas) e safrablau $1 \%$ (secções transversais) por 30 segundos, sendo, então, lavadas em água destilada e montadas em lâmina com glicerina 50\% (KRAUS; ARDUIM, 1997).

Foram analisadas uma lâmina por folha e 5 secções por lâmina, sendo observadas ao microscópio de luz acoplado à câmera digital com a qual foi realizada uma fotomicrografia de cada secção. Os parâmetros anatômicos quantitativos foram analisados por meio de software de análise de imagem (UTHSCSA-Imagetool) calibrado com régua microscópica fotografada nos mesmos aumentos das fotografias. Para cada parâmetro anatômico, foram realizadas 4 medições em cada fotografia, totalizando 20 campos amostrados por folha. Os parâmetros avaliados foram: espessura da epiderme da face abaxial (EAB) e adaxial (EAD), do mesofilo (EMF), da cutícula da face adaxial (CTA) e abaxial (CTB), da camada subepidérmica parenquimática das faces adaxial (CPAD) e abaxial (CPAB) e do floema (FL); diâmetro dos elementos condutores do xilema (DX) e dos canais secretores (CAV); número de vasos no xilema (NV); índice de vulnerabilidade de Carlquist (IVC); densidade estomática na face adaxial (DEAD) e abaxial (DEAB), índice estomático na face adaxial (IEAD) e abaxial (IEAB), funcionalidade estomática na face adaxial (FAD) e abaxial (FAB).

Para as análises biométricas, as folhas foram coletadas em sacos de papel, levadas ao laboratório de Anatomia Vegetal da Universidade Federal de Lavras e escaneadas em scanner de mesa. Posteriormente, as folhas foram secas em estufa de circulação forçada até peso constante e a massa seca foliar (MSF) avaliada em balança analítica. As imagens escaneadas das folhas foram utilizadas para medir as seguintes variáveis: área foliar (AF), comprimento (CF) e largura (LF) das folhas. A razão entre a área foliar e massa seca foliar foram utilizadas para calcular a área foliar específica (AFE), que foi utilizada como medida da esclerofilia foliar.

$O$ delineamento foi em DIC, com 10 repetições. Foi realizada a análise de variância com o teste de $\mathrm{F}$ para detectar as diferenças entre os tratamentos e o teste de Tukey para $\mathrm{p}<0,05$ para $\circ$ estudo das médias em software de análise estatística (Sisvar).

\section{RESULTADOS E DISCUSSÃO}

Os folíolos de $S$. molle em secção transversal apresentam epiderme formada por uma camada de células tabulares com espessamento das paredes periclinais externas, bem como uma cutícula espessa (Figura 1A). Ocorre a presença de uma camada subepidérmica parenquimática com células de formato, variando de tabular a, aproximadamente, isodiamétrico nas faces adaxial e abaxial, como ilustrado na Figura $1 \mathrm{~A}$ para a face adaxial e na Figura 1B para ambas as faces. O mesmo foi observado por Duarte et al. (2009) em Schinus terebinthifolius, contudo, por não terem sido realizados estudos ontogenéticos, que determinassem qual meristema dá origem a esse tecido, não é possível classificá-la como hipoderme. O mesofilo é isobilateral, tendendo a homogêneo, uma vez que o parênquima esponjoso é muito pouco evidente, apresentando seis camadas de células do parênquima clorofiliano, sendo três voltadas para a face adaxial e três para a face abaxial (Figura 1B). $O$ sistema vascular constitui-se de feixes colaterais (Figura 1C). Na margem dos folíolos, ocorre um canal secretor, com presença de colênquima na extremidade do bordo foliar (Figura 1D).

A nervura central apresenta dois canais secretores, podendo aparecer outros menores nas laterais dos canais principais (Figura 1E). Os canais são envolvidos por parênquima fundamental e associados com os tecidos vasculares na face adaxial. O floema é associado, diretamente, com o parênquima fundamental que envolve os canais secretores (Figura 1E). No centro da nervura, ocorre um grupamento de feixes vasculares de menor porte com orientação invertida, com o floema voltado para a face adaxial e o xilema para a face abaxial da nervura (Figura 1E). Os folíolos apresentam em secção paradérmica, estômatos anomocíticos e ciclocíticos e células epidérmicas com paredes anticlinais de contorno reto e com espessamento homogêneo (Figura 1F). Os folíolos são anfiestomáticos com os estômatos da face adaxial, geralmente, maiores e em menor quantidade que os da face abaxial.

O parênquima paliçádico presente na face adaxial da nervura central mostra-se interrompido por células de colênquima na região da nervura mediana (Figura 2A-C). Ocorre a presença de fibras floemáticas, envolvendo os canais secretores na face adaxial.

As variações ambientais em função da altura da folha na copa promoveram modificações na estrutura interna dos folíolos (Figura 2 e Tabelas 1, 2 e 3). A EAB foi maior nos folíolos do meio da copa em relação às 

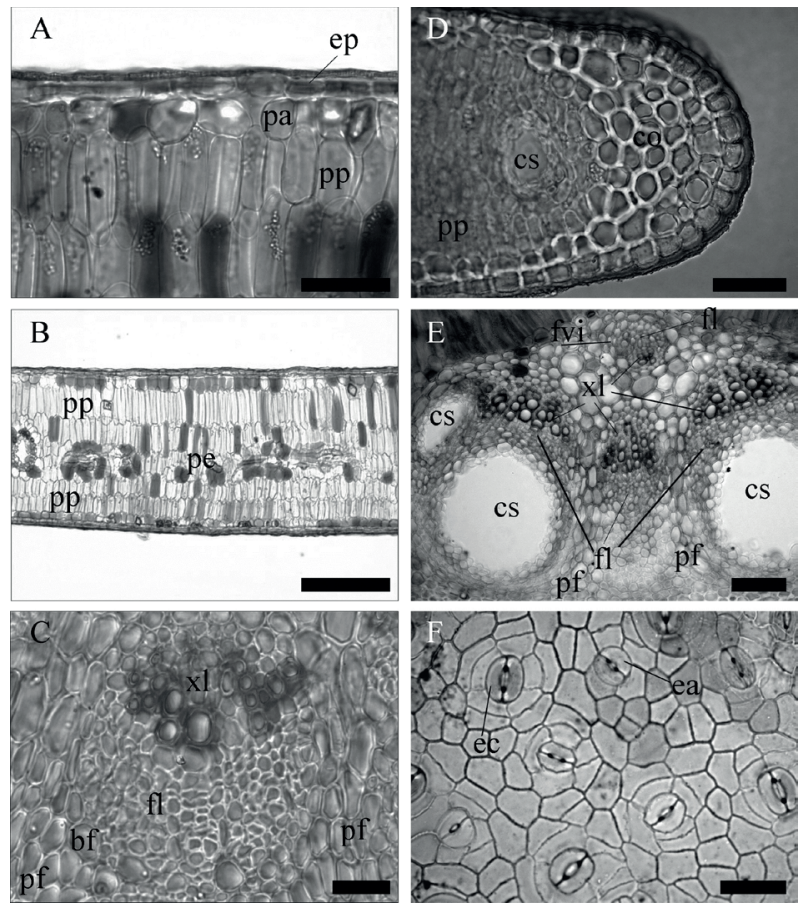

FIGURA 1 Secções transversais (A-E) e paradérmica da face abaxial $(F)$ de folíolos de $S$. molle. bf $=$ bainha do feixe vascular, $\mathrm{co}=$ colênquima, $\mathrm{cs}=$ canal secretor, ea $=$ estômato anomocítico, ec= estômato ciclocítico, ep= epiderme, fl= floema, $\mathrm{fvi}=$ feixe vascular invertido, pa= parênquima, $\mathrm{pe}=$ parênquima esponjoso, $\mathrm{pf}=$ parênquima fundamental, $\quad \mathrm{pp}=$ parênquima paliçádico, $\quad \mathrm{xl}=$ xilema. Barras $=50 \mu \mathrm{m}(\mathrm{A}, \mathrm{D}, \mathrm{E}, \mathrm{F}) ; 100 \mu \mathrm{m}(\mathrm{B}) \mathrm{e}$ $25 \mu \mathrm{m}$ (C).

FIGURE 1 Cross sections (A-E) and paradermic section of the abaxial face $(E)$ of $S$. molle plants leaflets. $\mathrm{bf}=$ vascular bundle sheet, $\mathrm{co}=$ collenchyma, $\mathrm{cs}=$ secretory channel, ea $=$ anomocitic stomata, ec= ciclocitic stomata, ep= epidermis, $\mathrm{fl}=$ phloem, $\mathrm{fvi}=$ turnover vascular bundle, pa= parenchyma, pe= spongy parenchyma, $\mathrm{pf}=$ ground parenchyma, $\mathrm{pp}=$ palisade parenchyma, $x \mathrm{l}=\mathrm{xylem}$. Bars $=50 \mu \mathrm{m}(\mathrm{A}$, $\mathrm{D}, \mathrm{E}, \mathrm{F}) ; 100 \mu \mathrm{m}(\mathrm{B})$ and $25 \mu \mathrm{m}(\mathrm{C})$.

da base e do ápice (Tabela 1), sendo que os folíolos do alto da copa exibiram os menores valores para essa característica, com uma redução de $15 \%$ em relação aos folíolos do meio. Para a EAD, não ocorreram diferenças significativas entre os folíolos das diferentes alturas na planta. A EMF exibiu aumento gradual da base para $\circ$ ápice da copa (Figura 2 D-F e Tabela 1). Ocorreu um aumento de $16 \%$ da base para o meio da copa e um incremento de $29 \%$ nos folíolos do alto da copa, em relação àquelas da base (Tabela 1). A CTA e CTB exibiram aumento nos folíolos do alto da copa em relação aos folíolos da base (Tabela 1). Ocorreu aumento de $70 \%$ em CTA nos folíolos do alto da copa

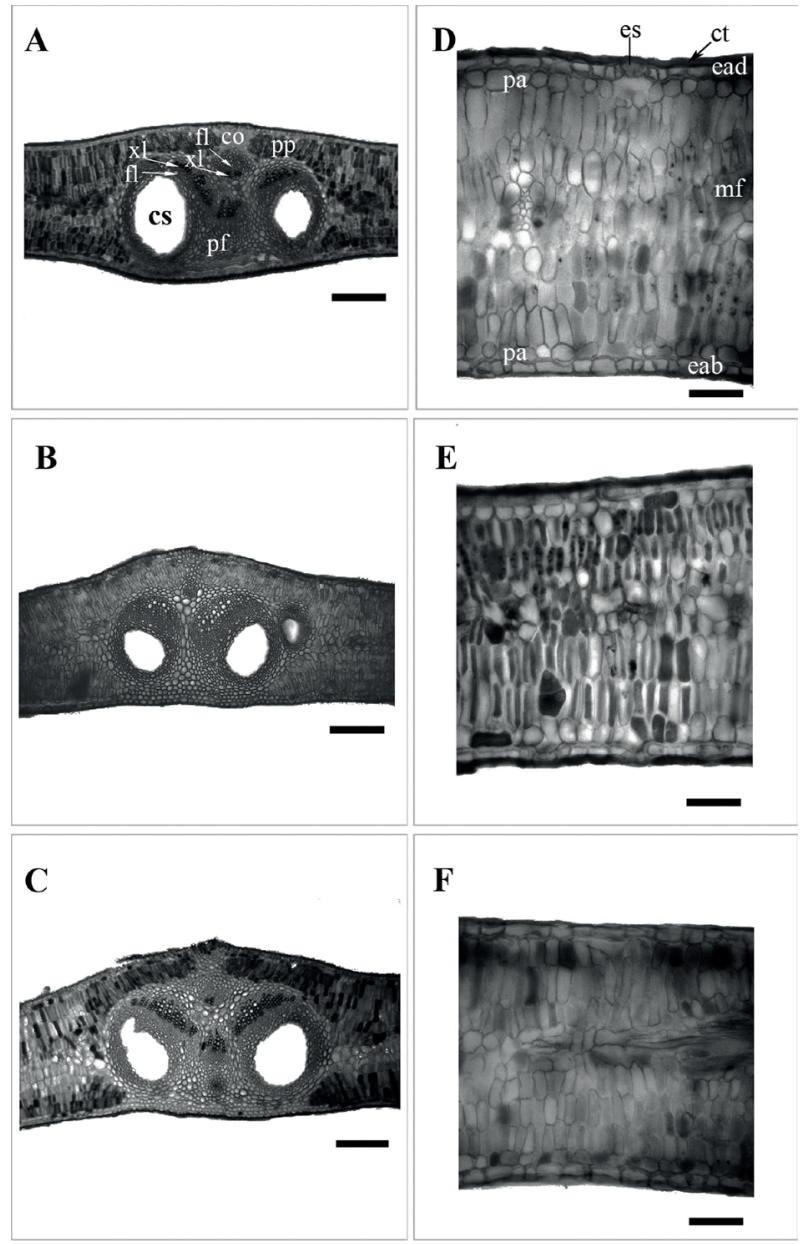

FIGURA 2 Secções transversais da nervura central (AC) e do limbo (D-F) dos folíolos de $S$. molle em diferentes alturas na copa. A e D= Alto da copa, B e $\mathrm{E}=$ Meio da copa e $\mathrm{C}$ e $\mathrm{F}=$ Base da copa. $\mathrm{co}=$ colênquima, $c s=$ canal secretor, $c t=$ cutícula, eab= epiderme da face abaxial, ead= epiderme da face adaxial, es= estômato, $\mathrm{fl}=$ floema, $\mathrm{mf}=$ mesofilo, $\mathrm{pa}=$ parênquima, $\mathrm{pf}=$ parênquima fundamental, $\mathrm{xl}=$ xilema. Barras $=50 \mu \mathrm{m}$.

FIGURE 2 Cross sections of the midrib (A-C) and leaf blade (D-F) of $S$. molle leaflets at different heights in the canopy. $A$ and $D=$ upper canopy, $B$ and $E=$ middle canopy and $\mathrm{C}$ and $\mathrm{F}=$ lower canopy. $\mathrm{Co}=$ collenchyma, cs $=$ secretory channels, $\mathrm{ct}=$ cuticle, eab $=$ abaxial face epidermis, ead $=$ adaxial face epidermis, es= stomata, $\mathrm{fl}=$ phloem, $\mathrm{mf}=$ mesophyll, $\mathrm{pa}=$ parenchyma, $\mathrm{pf}=$ ground parenchyma, $\mathrm{xl}=$ xylem,. Bars $=50 \mu \mathrm{m}$.

em relação aos folíolos da base, e $36 \%$ nos folíolos do meio em relação aos da base. A CTB foi $72 \%$ superior nos folíolos do alto em relação aos folíolos da base. A CPAD foi $30 \%$ menor nos folíolos do alto e meio da copa em relação aos da base, contudo, não ocorreram modificações na CPAB (Tabela 1). 
TABELA I Características anatômicas de folíolos de S. molle de diferentes alturas na copa.

TABLE I Anatomical characteristics of $S$. molle leaflets at different heights in the canopy.

\begin{tabular}{lccccccc}
\hline Posição & EAB $(\mu \mathrm{m})$ & EAD $(\mu \mathrm{m})$ & EMF $(\mu \mathrm{m})$ & CTA $(\mu \mathrm{m})$ & CTB $(\mu \mathrm{m})$ & CPAD $(\mu \mathrm{m})$ & CPAB $(\mu \mathrm{m})$ \\
\hline Alto & $11,12 \mathrm{c}$ & $10,15 \mathrm{a}$ & $242,3 \mathrm{a}$ & $8,75 \mathrm{a}$ & $7,13 \mathrm{a}$ & $16,16 \mathrm{c}$ & $13,83 \mathrm{a}$ \\
Meio & $13,17 \mathrm{a}$ & $09,40 \mathrm{a}$ & $218,4 \mathrm{~b}$ & $7,00 \mathrm{~b}$ & $7,85 \mathrm{a}$ & $17,80 \mathrm{~b}$ & $15,34 \mathrm{a}$ \\
Base & $12,28 \mathrm{~b}$ & $10,53 \mathrm{a}$ & $188,1 \mathrm{c}$ & $5,15 \mathrm{c}$ & $4,55 \mathrm{~b}$ & $22,57 \mathrm{a}$ & $12,68 \mathrm{a}$ \\
\hline
\end{tabular}

$E A B=$ espessura da epiderme da face abaxial, $E A D=$ espessura da epiderme da face adaxial, $E M F=$ espessura do mesofilo, $C T A=$ espessura da cutícula da face adaxial, $C T B=$ espessura da cutícula da face abaxial, $C P A D=$ camada subepidérmica parenquimática da face adaxial, $C P A B=c a m a d a$ subepidérmica parenquimática da face abaxial. As médias seguidas de mesma letra na coluna não diferem pelo teste de Tukey para $\mathrm{P}<0,05$.

TABELA 2 Características anatômicas da nervura central de folíolos de $S$. molle de diferentes alturas na copas.

TABLE 2 Anatomical characteristics of S. molle leaflet midribs at different heights in the canopy.

\begin{tabular}{lccccc}
\hline Posição & $\mathrm{DX}(\mu \mathrm{m})$ & $\mathrm{FL}(\mu \mathrm{m})$ & $\mathrm{CAV}(\mu \mathrm{m})$ & $\mathrm{NV}$ & $\mathrm{IVC}$ \\
\hline Alto & $12,51 \mathrm{a}$ & $23,15 \mathrm{a}$ & $103,25 \mathrm{a}$ & $84,20 \mathrm{a}$ & $0,15 \mathrm{~b}$ \\
Meio & $09,35 \mathrm{~b}$ & $18,95 \mathrm{~b}$ & $093,49 \mathrm{a}$ & $58,00 \mathrm{~b}$ & $0,17 \mathrm{~b}$ \\
Base & $13,36 \mathrm{a}$ & $21,77 \mathrm{a}$ & $101,34 \mathrm{a}$ & $73,00 \mathrm{a}$ & $0,20 \mathrm{a}$ \\
\hline
\end{tabular}

$\mathrm{DX}=$ diâmetro dos elementos condutores do xilema, $\mathrm{FL}=$ espessura do floema, $\mathrm{CAV}=$ diâmetro dos canais secretores, $\mathrm{NV}=$ número de vasos no xilema, IVC= índice de vulnerabilidade de Carlquist. As médias seguidas de mesma letra na coluna não diferem pelo teste de Tukey a $5 \%$ para $\mathrm{P}<0,05$.

TABELA 3 Características anatômicas da epiderme da face abaxial e adaxial de folíolos de $S$. molle em diferentes alturas na copa.

TABLE 3 Epidermal characteristics of the abaxial and adaxial surfaces of $S$. molle leaflets at different heights in the canopy.

\begin{tabular}{lcccccc}
\hline Posição & DEAD & DEAB & $\begin{array}{c}\text { IEAD } \\
(\%)\end{array}$ & $\begin{array}{c}\text { IEAB } \\
(\%)\end{array}$ & FAD & FAB \\
\hline Alto & 108,44 a & 128,96 a & 8,59 a & 09,05 a & 1,33 a & 1,28 b \\
Meio & 100,82 a & 103,17 b & 8,00 a & 10,44 a & 1,25 a & 1,45 a \\
Base & 094,38 a & 100,82 b & 8,11 a & 09,83 a & 0,97 b & 1,03 c \\
\hline
\end{tabular}

$D E A D=$ densidade estomática na face adaxial, $D E A B=$ densidade estomática na face abaxial, IEAD= índice estomático na face adaxial, $\mathrm{IEAB}=$ índice estomático na face abaxial, $\mathrm{FAD}=$ funcionalidade estomática na face adaxial, $F A B=$ funcionalidade estomática na face abaxial. As médias seguidas de mesma letra na coluna não diferem pelo teste de Tukey a $5 \%$ para $\mathrm{P}<0,05$.

O DX exibiu diferenças nos folíolos de diferentes posições da copa, sendo cerca de $30 \%$ menor nos folíolos do meio em relação à base e ao alto da copa (Tabela 2). O FL foi $22 \%$ maior nos folíolos do alto da copa em relação aos folíolos do meio, sendo que esses valores foram semelhantes aos encontrados para os folíolos da base (Tabela 2). Não ocorreram diferenças para a CAV nos folíolos das diferentes alturas na copa. O NV exibiu modificações nas diferentes alturas, e, associado com o DX, produziu diferenças no IVC, que reduziu em $25 \%$ nos folíolos do alto e do meio da copa em relação aos folíolos da base (Tabela 2 ).
As modificações encontradas nos tecidos foliares em secção transversal ilustram diferenças nas adaptações ecológicas das folhas ao longo da copa. Os folíolos do alto da copa exibiram características de folhas de sol, visto que, essa região está sujeita a uma maior quantidade de radiação solar e de incidência de vento (LARCHER, 2004). De modo semelhante, Cano et al. (20I3) observaram que a morfologia foliar de Quercus petraea e Fagus sylvatica foi determinada pelo ambiente de luz em diferentes camadas do dossel das árvores. Pode-se concluir que os folíolos do alto da copa exibiram maior espessura da cutícula para reduzir a perda de água, relacionada com a sobrevivência da planta e às condições mais xéricas, resultado associado, também, ao aumento na densidade estomática e aumento na espessura do mesofilo (BOEGER; WISNIEWSKI, 2003). O maior espessamento do mesofilo das folhas em condições de deficiência hídrica é relatado para diferentes espécies, como para plantas de café submetidas à seca (GRISI et al., 2008). Ocorreu, juntamente com uma maior espessura da cutícula, redução na espessura da camada subepidérmica parenquimática, que era bastante superior nos folíolos da base da copa. Isso pode estar relacionado a um aumento do clorênquima, que pode promover maior eficiência do ponto de vista fotossintético ao aproveitar a maior radiação incidente nesses folíolos.

O IVC está diretamente relacionado com a eficiência da condução de água no xilema por reduzir a cavitação (CALRQUIST, 1975) essa característica está diretamente relacionada com o aumento no número de vasos e a redução do diâmetro dos vasos de metaxilema (FIELDES; GERHARDT, 1998). O IVC pode variar de forma apreciável em função das condições ambientais, como o alagamento, em folhas (SOUZA et al., 2010) e em raízes de milho (PEREIRA et al., 2008; SOUZA et al., 2009) estando relacionadas a uma melhor condutividade hidráulica. Dessa forma, os elementos xeromórficos verificados nos folíolos do alto da copa se confirmam e, estes apresentam adaptações para reduzir a perda de água. O aumento do FL nos folíolos do alto da copa pode favorecer a translocação de fotoassimilados dessas folhas 
para o resto da planta. Portanto, os folíolos do alto da copa podem exibir maior eficiência para a condução de água e translocação de fotoassimilados, que os folíolos do meio e da base da copa.

Não ocorreram diferenças na DEAD dos folíolos em diferentes posições da copa, por outro lado, o DEAB aumentou em $28 \%$ nos folíolos do alto da copa, em relação aos folíolos da base e do centro (Tabela 3). O IEAD e IEAB não apresentaram diferenças para as diferentes alturas dos folíolos, contudo, o IEAB foi superior em relação ao IEAD (Tabela 3). O FAD foi superior $37 \%$ nos folíolos do meio e do alto da copa em relação aos folíolos da base (Tabela 3). A FAB aumentou em $25 \%$ nos folíolos do alto e em $45 \%$ nos folíolos do meio em relação aos folíolos da base da copa (Tabela 3).

Os folíolos de S. molle possuem estômatos do mesmo tipo relatado para outras plantas desse gênero, contudo, com valores muito superiores para os diâmetros polar e equatorial e índice estomático também superior, em comparação com os encontrados para Schinus longifolia var. longifolia (PERROTA; ARAMBARRI, 2004). A estrutura do folíolo em secção transversal também difere de S. longifolia que possui mesofilo dorsiventral, em comparação com o mesofilo isobilateral encontrado para S. molle, além de uma estrutura diferenciada na nervura central em comparação àquela encontrada por Perrota e Arambarri (2004) para S. longifolia. Por outro lado, Schinus weinmanniifolia apresentou estrutura semelhante no mesofilo e na nervura central (ARAMBARRI et al., 2008). Esses resultados demonstram a importância do conhecimento da estrutura interna das diferentes espécies do gênero, que exibem diferenças interespecíficas na estrutura anatômica e, a possibilidade da utilização da anatomia na separação das espécies do gênero, fato de grande importância para a correta utilização da planta. De acordo com Metcalfe e Chalk (1983), os caracteres anatômicos dos órgãos vegetativos das plantas servem como dados adicionais às características morfológicas externas, podendo ser usados para resolver problemas taxonômicos. Dessa forma, as características descritas no presente trabalho para S. molle podem contribuir para a identificação e taxonomia da espécie.

A maior densidade de estômatos nos folíolos do alto da copa, associados com a maior funcionalidade observada conferem maior eficiência para as trocas gasosas. O aumento na densidade estomática proporciona maior eficiência na captura $\mathrm{CO}_{2}$, evitando, que esse gás limite a fotossíntese (KUNDU; TIGERSTEDT, 1999). O índice estomático não se modificou, pois essa característica pode ser relativamente constante para a espécie. Além disso, Paiva et al. (2003) não observaram diferenças significativas no índice estomático em plantas de Tradescantia pallida, em função de diferentes condições de radiação. Contudo, a maior densidade estomática reflete em mais estômatos para as trocas gasosas e a maior funcionalidade observada pode permitir a captação de $\mathrm{CO}_{2}$ de forma mais eficiente.

Os estudos anatômicos, além de contribuírem para a identificação da espécie medicinal podem ser utilizados para avaliar o potencial plástico da espécie frente a diferentes condições ambientais (MILLANI et al., 2010; PAIVA et al., 2003; SABBI et al., 20I0). Pode-se verificar que ocorrem diferenças nos folíolos de S. molle em função da altura da folha na copa e as propriedades medicinais podem variar, de acordo com essas modificações, demonstrando plasticidade morfológica. Segundo Castro et al. (2006, 2009), variações ambientais como na intensidade de radiação influenciam a anatomia foliar e os teores dos compostos ativos encontrados em plantas com potencial medicinal. No entanto, estudos sobre as características anatômicas das plantas de interesse medicinal e industrial ainda são escassos (MARTINS et al., 2010). Dessa forma, é necessário conhecer quais as características foliares que podem ser mais interessantes dependendo do uso que se deseja para a planta.

Além das modificações anatômicas encontradas, as folhas são morfologicamente distintas em função da altura que ocupam na copa de S. molle. As folhas da base da copa possuem uma AF 4I, 32\% maior em comparação com as folhas do alto da copa, as folhas da região mediana possuem área foliar intermediária, sendo 10,09\% menores em relação às folhas da base da copa (Tabela 4). Resultado semelhante pode ser observado para a LF e o $\mathrm{CF}$, sendo que as folhas de $\mathrm{S}$. molle apresentam redução gradual em suas dimensões à medida que se observam folhas de posições mais altas na copa (Tabela 4). As folhas de $S$. molle apresentam massa seca menor, quando amostradas no alto da copa, em comparação com o meio e a base, sendo a massa seca das folhas da base e meio da copa $28,37 \%$ maiores em comparação com o alto da copa (Tabela 4). A AFE apresenta modificações no alto em comparação com o meio e a base da copa, sendo essa variável 10,23\% maior nas folhas do meio e base da copa em comparação com o alto (Tabela 4).

Posições mais altas na copa de plantas arbóreas podem promover condições com maior intensidade de radiação, menor disponibilidade hídrica e nutricional (DIAS et al., 2007; ENGLAND; ATTIWILL, 2006; HUBBARD et al., 1999; KIRA; YODA, 1989). Segundo 
Sabbi et al. (2010), folhas de plantas de S. terebinthifolius expostas a ambientes com maior intensidade de radiação promovem folhas com menor área foliar e área foliar específica. Em resposta a ambientes mais xéricos e com maior intensidade de radiação folhas com menor área foliar e AFE são comumente encontradas e relacionadas à redução na taxa de transpiração. Dessa forma, corroborando os dados obtidos para anatomia foliar, onde se verificou maior espessura do mesofilo, as folhas de S. molle apresentam-se mais escleromorfas e mais adaptadas a condições de maior intensidade de radiação e menor disponibilidade hídrica, podendo refletir em suas condições fisiológicas. Além disso, esses resultados estão de acordo com as características atribuídas às folhas de sol, como resultado da ação morfogenética da radiação solar (LIMA JÚNIOR et al., 2006) sobre os tecidos foliares.

TABELA 4 Características biométricas das folhas de S. molle em diferentes alturas na copa.

TABLE 4 Biometrical characteristics of $S$. molle leaves at different heights in the canopy.

\begin{tabular}{lccccc}
\hline Posição & $\begin{array}{c}\text { AF } \\
\left(\mathrm{cm}^{2}\right)\end{array}$ & $\begin{array}{c}\text { LF } \\
(\mathrm{cm})\end{array}$ & $\begin{array}{c}\mathrm{CF} \\
(\mathrm{cm})\end{array}$ & $\begin{array}{c}\text { MSF } \\
(\mathrm{g})\end{array}$ & $\begin{array}{c}\text { AFE } \\
\left(\mathrm{cm}^{2} \cdot \mathrm{g}^{-1}\right)\end{array}$ \\
\hline Alto & $26,003 \mathrm{c}$ & $7,486 \mathrm{c}$ & $13,335 \mathrm{c}$ & $0,349 \mathrm{~b}$ & $76,776 \mathrm{~b}$ \\
Meio & $33,378 \mathrm{~b}$ & $8,162 \mathrm{~b}$ & $14,809 \mathrm{~b}$ & $0,404 \mathrm{a}$ & $84,344 \mathrm{a}$ \\
Base & $36,747 \mathrm{a}$ & $8,786 \mathrm{a}$ & $15,921 \mathrm{a}$ & $0,448 \mathrm{a}$ & $84,629 \mathrm{a}$ \\
\hline
\end{tabular}

$\mathrm{AF}=$ área foliar, $\mathrm{MSF}=$ massa seca foliar, $\mathrm{AFE}=$ área foliar específica, $\mathrm{LF}=$ largura da folha, $\mathrm{CF}=$ comprimento da folha. As médias seguidas de mesma letra na coluna não diferem pelo teste de Tukey a $5 \%$ para $\mathrm{P}<0,05$.

De acordo com Boeger e Wisniewski (2003), a área foliar, a espessura da lâmina, e a densidade estomática são características plásticas e com uma forte relação entre si. Assim como para S. molle, esses autores observaram que a espessura do mesofilo apresentou uma relação inversamente proporcional à área foliar e uma relação diretamente proporcional à densidade estomática em folhas de espécies arbóreas em três estádios secionais distintos de uma floresta ombrófila. Além disso, a densidade estomática também está intimamente relacionada à área foliar. Desse modo, a redução da área foliar pode ter promovido o aumento no número de estômatos por unidade de área epidérmica sem, necessariamente, uma maior produção de estômatos nos folíolos do alto da copa.

\section{CONCLUSÕES}

Os folíolos de S. molle diferem, anatomicamente, de outras espécies do gênero, com epiderme unisseriada, estômatos anomocíticos e ciclocíticos, mesofilo isobilateral e camada subepidérmica em ambas as faces da epiderme; presença de canais secretores e colênquima.

Ocorrem modificações na morfologia externa com folhas menores e mais escleromorfas na posição mais alta da copa de plantas de S. molle, além de modificações nas espessuras da cutícula e do mesofilo, na vulnerabilidade do sistema vascular, espessura do floema e na densidade estomática, de acordo com a altura em que as folhas estão presentes na copa, em função de variações ambientais. Essas diferenças podem influenciar as propriedades fisiológicas e medicinais.

\section{AGRADECIMENTOS}

A Coordenação de Aperfeiçoamento de Pessoal de Nível Superior, ao Conselho Nacional de Desenvolvimento Científico e Tecnológico e à Fundação de Amparo à Pesquisa do Estado de Minas Gerais.

\section{REFERÊNCIAS}

ARAMBARRI, A. N.; FREIRE, S. E.; COLARES, M. N.; BAYÓN, N. D.; NOVOA, M. C.; MONRI, C. Leaf anatomy of medicinal shrubs and trees from gallery forests of the paranaense province (Argentina): part I. Boletin de la Sociedad Argentina de Botánica, Córdoba, v. 4I, n. 3/4, p. 233-268, 2006.

ARAMBARRI, A. M.; FREIRE, S. E.; COLARES, M. N.; BAYÓN, N. D.; NOVOA, M. C.; MONTI, C.; STENGLEIN, S. A. Leaf anatomy of medicinal shrubs and trees from Misiones forest of the Paranaense Province (Argentina): part 2. Boletín de la Sociedad Argentina de Botánica, Córdoba, v. 43, n. I/2, p. 3I-60, 2008.

BEZERRA, A. M. E.; MEDEIROS FILHO, S.; OLIVEIRA, L. D. M.; SILVEIRA, E. R. Produção e composição química da macela em função da época de colheita. Horticultura Brasileira, Brasília, v. 26, n. I, p. 26-29, jan./mar. 2008.

BOEGER, M. R. T.; WISNIEWSKI, C. Comparação da morfologia foliar de espécies arbóreas de três estádios sucessionais distintos de floresta ombrófila densa (Floresta Atântica) no sul do Brasil. Revista Brasileira de Botânica, São Paulo, v. 26, n. I, p. 6I-72, mar. 2003.

CAMARGO, I. P. de; CASTRO, E. M. de; GAVILANES, M. L. Aspectos da anatomia e morfologia de amêndoas e plântulas de castanheira-do-brasil. Cerne, Lavras, v. 6, n. 2, p. II-I8, jul./dez. 2000.

CANO, F. J.; SÁNCHEZ-GÓMEZ, D.; RODRÍGUEZCALCERRADA, J.; WARREN C. R.; GIL, L.; ARANDA, I. Effects of drought on mesophyll conductance and photosynthetic limitations at different tree canopy layers. Plant, Cell and Environment, Malden, v. 36, n. I I, p. I-20, Apr. 2013. 
CARLQUIST, S. Ecological strategies of xylem evolution. Berkeley: University of California, 1975. 259 p.

CASTRO, E. M.; PEREIRA, F. J.; PAIVA, R. Histologia vegetal: estrutura e função de órgãos vegetativos. Lavras: UFLA, 2009. $234 p$

CASTRO, E. M.; PINTO, J. E. B. P.; BERTOLUCCI, S. K. V.; MALTA, M. R.; CARDOSO, M. G.; SILVA, F. A. M. Coumarin contents in young Mikania glomerata plants (Guaco) under different radiation levels and photoperiod. Acta Farmaceutica Bonaerense, Buenos Aires, v. 25, n. 3, p. 387-392, mar. 2006.

DIAS, J.; PIMENTA, J. A.; MEDRI, M. E.; BOEGER, M. R. T.; FREITAS, C. T. Physiological aspects of sun and shade leaves of Lithraea molleoides (Vell.) Engl. (Anacardiaceae). Brazilian Archives of Biology and Technology, Curitiba, v. 50, n. I, p. 91-99, Jan. 2007

DUARTE, M. R. L.; SCHRODER, L. M.; TOLEDO, M. G.; YANO, M.; MACHADO, A. A.; MODOLO, A. K. Comparative leaf anatomy of species of aroeira: Myracrodruon urundeuva ALLEMÃO and Schinus terebinthifolius RADDI. Visão Acadêmica, Curitiba, v. 10, n. I, p. 18-28, jan./jun. 2009.

ENGLAND, J. R.; ATTIWILL, P. M. Changes in leaf morphology and anatomy with tree age and height in the broadleaved evergreen species, Eucalyptus regnans F. Muell. Trees, Vancouver, v. 20, n. I, p. 79-90, Jan. 2006.

FIELDES, M. A.; GERHARDT, K. E. Flax guaiacol peroxidases can be used to illustrate the possibility of misinterpreting the effects of stress on the activity of developmentally regulated enzymes. Plant Science, Davis, v. I32, n. I, p. 89-99, Feb. 1998.

GRISI, F. A.; ALVES, D. J.; CASTRO, E. M. de; OLIVEIRA, C. de; BIAGIOTTIS, G.; MELO, L. A. de. Avaliações anatômicas foliares em mudas de café 'Catuaí' e 'Siriema' submetidas ao estresse hídrico. Ciência e Agrotecnologia, Lavras, v. 32, n. 6, p. 1730-36, nov./dez. 2008.

HUBBARD, R. M.; BOND, B. J.; RYAN, M. G. Evidence that hydraulic conductance limits photosynthesis in old Pinus ponderosa trees. Tree Physiology, Durham, v. 19, n. 3, p. 165-172, Mar. 1999

JOHANSEN, D. A. Plant microtechinique. $2^{\text {nd }}$ ed. New York: McGraw-Hill, 1940. 523 p.

KING, D. A. The adaptive significance of tree height. The American Naturalist, Chicago, v. I35, n. 6, p. 809-829, June 1990.

KIRA, T.; YODA, K. Vertical stratification in microclimate. In: LIETH, H.; WERGER, M. J. A. (Ed.). Tropical rain forest ecosystems: biogeographical and ecological studies. Amsterdam: Elsevier, 1989. p. 55-7I
KRAUS, J. E.; ARDUIM, M. Manual básico de métodos em morfologia vegetal. Rio de Janeiro: Seropédica, 1997. $198 \mathrm{p}$.

KUBÍNOVÁ, L. Stomata and mesophyll characteristics of barley leaf as affected by light: stereological analysis. Journal of Experimental Botany, Oxford, v. 42, n. 8, p. 995-I00I, May 1991.

KUNDU, S. K.; TIGERSTEDT, P. M. A. Variation in net photosynthesis, stomatal characteristics, leaf area and whole-plant phytomass production among ten provenances of neem (Azadirachta indica). Tree Physiology, Durham, v. 19, n. I, p. 47-52, Jan. 1999.

LARCHER, W. Ecofisiologia vegetal. São Carlos: Rima, 2004. $531 \mathrm{p}$.

LIMA JÚNIOR, É. C.; ALVARENGA, A. A.; CASTRO, E. M.; VIEIRA, C. V.; BARBOSA, J. P. R. A. D. Aspectos fisioanatômicos de plantas jovens de Cupania vernalis Camb. submetidas a diferentes níveis de sombreamento, Revista Árvore, Viçosa, MG, v. 30, n. I, p. 33-4I, jan./ fev. 2006

LORENZI, H. Manual de identificação e cultivo de plantas arbóreas nativas do Brasil. Nova Odessa: Plantarum, 1992. $352 \mathrm{p}$.

MACHADO, D. G.; BETTIO, L. E. B.; CUNHA, M. P.; SANTOS, A. R. S.; PIZZOLATTI, M. G.; BRIGHENTE, I. M. C.; RODRIGUES, A. L. S. Antidepressant-like effect of rutin isolated from the ethanolic extract from Schinus molle $\mathrm{L}$. in mice: evidence for the involvement of the serotonergic and noradrenergic systems. European Journal of Pharmacology, Utrecht, v. 587, n. I/3, p. 163-168, June 2008.

MARONGIU, B.; PORCEDDA, A. P. S.; CASU, R.; PIERUCCI, P. Chemical composition of the oil and supercritical $\mathrm{CO}_{2}$ extract of Schinus molle L. Flavour and Fragrance Journal, Malden, v. 19, n. 6, p. 554-558, Nov./Dec. 2004.

MARTINS, M. B. G.; CARAVANTE, A. L. C.; GLÓRIA, B. A. da; SOARES, M. K. M.; MOREIRA, R. R. D.; SANTOS, L. E. Caracterização anatômica e fitoquímica de folhas e rizomas de Hedychium coronarium J. König (Zingiberaceae). Revista Brasileira de Plantas Medicinais, Botucatu, v. I2, n. 2, p. 179-187, abr./jun. 2010.

MELO, H. C.; CASTRO, E. M. de; SOARES, A. M.; MELO, L. A.; ALVES, J. D. Alterações anatômicas e fisiológicas em Setaria anceps Stapf ex Massey e Paspalum paniculatum L. sob condições de déficit hídrico. Hoehnea, São Paulo, v. 34, n. 2, p. 145-53, abr./jun. 2007.

METCALFE, C. R.; CHALK, L. Anatomy of the dicotyledons: wood struture and conclusion of the general introduction. New York: Oxford University, I 983. v. 2. 
MILLANI, A. A.; ROSSATTO, D. R.; RUBIN-FILHO, C. J.; KOLB, R. M. Análise de crescimento e anatomia foliar da planta medicinal Ageratum conyzoides L. (Asteraceae) cultivada em diferentes substratos. Revista Brasileira de Plantas Medicinais, Botucatu, v. 12, n. 2, p. 127-134, abr./ jun. 2010.

PAIVA, E. A. S.; ISAIAS, R. M. S.; VALE, F. H. A.; UEIROZ, C. G. $S$. The influence of light intensity on anatomical structure and pigment contents of Tradescantia pallida (Rose) Hunt. cv. Purpurea Boom (Commelinaceae) Leaves. Brazilian Archives of Biology and Technology, Curitiba, v. 46, n. 4, p. 617-624, Dec. 2003.

PEREIRA, F. J.; CASTRO, E. M. de; SOUZA, T. C. de; MAGALHÃES, P. C. Evolution of the root anatomy of 'Saracura' maize in successive selection cycles. Pesquisa Agropecuária Brasileira, Brasília, v. 43, n. 12, p. I649I656, dez. 2008.

PERROTA, V. G.; ARAMBARRI, A. N. Schinus longifolia var. longifolia (Anacardiaceae): anatomía foliar y caulinar. Acta Farmacéutica Bonaerense, Buenos Aires, v. 23, n. 2, p. |42-I27, 2004.
SABBI, L. B. C.; ÂNGELO, A. C.; BOEGER, M. R. Influência da luminosidade nos aspectos morfoanatômicos e fisiológicos de folhas de Schinus terebinthifolius Raddi (Anacardiaceae) implantadas em duas áreas com diferentes graus de sucessão, nas margens do Reservatório Iraí, Paraná, Brasil. Iheringia Série Botânica, Porto Alegre, v. 65, n. 2, p. I7|-|8I, dez. 2010.

SANTOS, A. C. A. dos; ROSSATO, M.; AGOSTINI, F; ALMEIDA, M. L. de; PAULETTI, G. F.; SERAFINI, L. A.; MOYNA, P.; DELLACASSA, E. Caracterização química de populações de Schinus molle L. do Rio Grande do Sul. Revista Brasileira de Biociências, Porto Alegre, v. 5, n. S2, p. I014-1016, 2007.

SOUZA, T. C. de; CASTRO, E. M. de; PEREIRA, F. J.; PARENTONI, S. N.; MAGALHAES, P. C. Morpho-anatomical characterization of root in recurrent selection cycles for flood tolerance of maize (Zea mays L.). Plant Soil and Environment, Praha, v. 55, n. I I, p. 504-5I0, Nov. 2009.

SOUZA, T. C. de; MAGALHÃES, P. C.; PEREIRA, F. J.; CASTRO, E. M. de; SILVA, J. M. da; PARENTONI, S. N. Leaf plasticity in successive selection cycles of 'Saracura' maize in response to periodic soil flooding. Pesquisa Agropecuária Brasileira, Brasília, v. 45, n. I, p. 16-24, jan. 2010. 